\title{
Covering all the bases: preclinical development of an effective Staphylococcus aureus vaccine
}

\section{Ingrid L. Scully, Paul A. Liberator, Kathrin U. Jansen and Annaliesa S. Anderson*}

Pfizer Vaccine Research and Development Unit, Pearl River, NY, USA

Edited by:

Fabio Bagnoli, Novartis Vaccines, Italy

Reviewed by:

Emilio Luis Malchiodi, University of Buenos Aires, Argentina

Alice Nyakeriga, Texas Tech University, USA

\section{*Correspondence:}

Annaliesa S. Anderson, Pfizer Vaccine Research and Development Unit, 401 North Middletown Road, Pearl River, NY 10965, USA

e-mail: annaliesa.anderson@

pfizer.com
A key aspect of the pathogenesis of the Gram positive bacterium Staphylococcus aureus is its ability to rapidly adapt to the host environment during the course of an infection. To successfully establish infection, the organism deploys a variety of survival and immune evasion strategies, ranging from the acquisition of essential nutrients and expression of adhesins, which promote colonization and survival, to the elaboration of virulence factors such as capsule, which aids host immune evasion. The ability of $S$. aureus to deploy different virulence factors must be taken into account for $S$. aureus vaccine design. Here, we present a strategy for designing an effective vaccine against $S$. aureus disease by evaluating vaccine candidate performance in multiple in vivo models targeted to mimic aspects of human disease, and by co-development of functional in vitro immunoassays that measure the neutralization of relevant $S$. aureus virulence factors.

Keywords: vaccine, Staphylococcus aureus, clumping factor A, preclinical models, immunoassays, capsular polysaccharide conjugates, manganese transport protein $\mathrm{C}$

\section{INTRODUCTION}

One of the major challenges in developing a vaccine for Staphylococcus aureus is the organism's ability to rapidly adapt to the host microenvironment. The Gram positive organism S. aureus is notorious for its diverse array of virulence factors, adaptation, and potential to change its surface antigen repertoire quickly (1).

The medical need for an $S$. aureus vaccine is clear. S. aureus is carried asymptomatically in the nares of $20-50 \%$ of the general population (2). S. aureus causes a wide spectrum of disease, ranging from relatively mild skin infections, such as carbuncles, to life-threatening wound and bloodstream infections (3). S. aureus is recognized as a leading cause of morbidity and mortality in both healthcare-associated and community settings. In surgical patients in particular, these infections carry high mortality rates; survivors of $S$. aureus surgical infections require an additional 13-17 days in the hospital, significantly increasing healthcare costs (4). The burden of $S$. aureus disease is exacerbated by antibiotic-resistant $S$. aureus isolates, highlighting the need for an effective prophylactic vaccine.

Specialized host microenvironments present obstacles for $S$. aureus to establish a productive infection. For example, in the blood, the organism must avoid ingestion and killing by phagocytes, especially neutrophils. In contrast, in a surgically induced wound, there are fewer neutrophils, at least initially, but nutrients are extremely limited and S. aureus must adhere to host surfaces. S. aureus possesses a variety of means to both colonize the host and evade the immune system by inhibiting phagocytic uptake and killing. The bacterium has developed multiple additional virulence factors to enable it to adapt and survive in a variety of host niches and as a result, to cause a multitude of diverse infection pathologies. To establish and sustain infection in the host, $S$. aureus needs to:
- Find a means of entry into the host by breaching the protective physical barriers to infection (skin, mucosa), or by entering a lesion, such as those created during surgery or traumatic injury.

- Obtain the essential nutrients for growth that are restricted in the host, such as iron and manganese, by expressing iron acquisition receptors, such as IsdB (5), and manganese uptake receptors, such as the $\mathrm{ABC}$ transporter MntABC (6).

- Adhere to extracellular matrix components and host cells. $S$. aureus can express multiple adhesion factors, including fibronectin-binding proteins (FnBPA, FnBPB) $(7,8)$, fibrinogenbinding proteins, also known as "clumping factors" (ClfA, ClfB) $(9,10)$, and collagen-binding protein (Cna) (11).

- Evade immune killing by producing an anti-phagocytic polysaccharide capsule (CP5 or CP8) (12) and elaborating a number of proteins that can interfere with antibody and complement binding (SpA, Sbi, SCIN) (13-15), phagocytic uptake, and killing in the phagolysosome. In addition, S. aureus can evade immune killing by producing multiple toxins that are either lethal to immune cells, such as alpha toxin and PantonValentine leukocidin (PVL), or act as superantigens, such as toxic shock syndrome toxin (TSST) and staphylococcal enterotoxin B (SEB) (16-18).

These different mechanisms of pathogenesis render S. aureus a challenging vaccine target. Thus, an effective vaccine to prevent $S$. aureus disease must contain antigens carefully selected to interrupt S. aureus pathogenesis using a multipronged approach. Currently there is no licensed vaccine against $S$. aureus infection and no clinically demonstrated correlate of protection against S. aureus.

\section{IMMUNE DEFENSES AGAINST S. AUREUS INFECTION}

The human host has several mechanisms to prevent $S$. aureus infection. These include mucosal and epithelial layers that act as 
a barrier to infection, the sequestration of essential nutrients to prevent bacterial survival and replication, the elaboration of danger signals in response to microbial products to activate the innate immune response and engulfment and killing of bacteria by professional phagocytes, such as neutrophils. In addition, adaptive immune components such as antibodies and $\mathrm{T}$ cells can act to prevent infection.

Humans can be persistently colonized with S. aureus and as such, there can be a constant interaction between the bacteria and the host immune system. This is supported by the observation that all adults have pre-existing binding antibodies to $S$. aureus antigens, including capsule and ClfA (19). However, functional antibodies that facilitate the opsonophagocytic killing of staphylococci by professional phagocytes [particularly neutrophils (20, 21)] and functional antibodies that neutralize virulence factors are absent in the vast majority of the human population. The importance of bacterial killing to prevent and/or resolve infections is underscored by the increased rates of infection that are observed for subjects with immunological disorders. The close link between defects in clearance and the risk of disease supports the hypothesis that if a vaccine generates adequate levels of functional antibodies in subjects with competent effector cells, these individuals are more likely to be protected at times of risk for an infection.

Polymorphonuclear neutrophils (PMNs) are the primary cellular defense against staphylococcal infections. These effector cells are highly efficient at killing phagocytosed pathogens. Phagocytosis is the binding and ingestion of bacteria, which can be facilitated by opsonization of the microbial surfaces with antibody and/or complement (22). Neutrophils recognize many molecules produced by $S$. aureus, such as lipoteichoic acid (LTA) and CpG DNA, which interact with TLRs on the neutrophils to promote phagocytosis $(23,24)$. Neutrophils express on their cell surfaces both complement receptors that bind complement-opsonized bacteria, and Fc receptors that bind the Fc region of antibody-coated bacteria. Once bound to the neutrophils, the bacteria are engulfed into an intracellular phagosome. This is followed by neutrophilinitiated mechanisms to kill the bacteria within the phagosome. Phagocytosis activates membrane bound NADPH-dependent oxidase to initiate a "respiratory burst," which generates high levels of reactive oxygen species (ROS, e.g., superoxide radicals, hydrogen peroxide, and hydroxyl radicals) to kill the engulfed microorganisms. In addition, the fusion of cytoplasmic granules with the bacteria-containing phagosome results in the release of preformed anti-microbial peptides, proteases, and $\alpha$-defensins with potent microbicidal activity (25).

Individuals with PMN defects have a higher incidence of $S$. aureus disease. Examples of neutrophil dysfunction include frank neutropenia (26), chronic granulomatous disease, in which neutrophils are unable to generate a functional respiratory burst (27-29), and Chediak-Higashi Syndrome, in which individuals have neutrophils with reduced chemotaxis and phagolysosome function (30). Subjects with defects in non-antibody-mediated clearance mechanisms, such as those with mutations in the pattern recognition receptor TLR2 (31) or defects in the complement pathway (32) cannot effectively clear staphylococci and thus are more susceptible to $S$. aureus infections. Individuals with defective STAT3 signaling proteins have also been shown to be more prone to $S$. aureus infections due to the inability to generate IL17-producing Th17 cells, which results in diminished neutrophil recruitment and function (33-35).

Antibody-mediated clearance mechanisms driven by the adaptive immune system, in which antibody-secreting B cells and cytokine-secreting and cytolytic $\mathrm{T}$ cells play a key role, are also important in the prevention of staphylococcal disease. For example, individuals with immune defects impairing the ability to produce functional antibodies, such as acquired immune deficiency syndrome (36), immature immune systems due to premature birth (37), or defects in immunoglobulin production, all have increased susceptibility to staphylococcal infections $(38,39)$. In males with $\mathrm{X}$-linked agammaglobulinemia, recurrent pyogenic infections that are often caused by $S$. aureus begin to occur within the first year of life after maternal IgG has been exhausted (40). Therefore, an effective $S$. aureus vaccine will likely require that a functional antibody response is elicited to enhance phagocyte-mediated killing of the organism. Functional antibody responses require the concomitant development of $\mathrm{T}$ cell help provided by $\mathrm{CD} 4^{+} \mathrm{T}$ cells. In addition, cytokines secreted by $\mathrm{T}$ helper cells (both Th1 and Th17) have been shown to enhance neutrophil effector function, so vaccine-induced Th1 and/or Th17 responses may also be beneficial in preventing $S$. aureus-mediated disease (41). Overall, these findings support the requirement for functional antibodies and neutrophil effector cell function to prevent $S$. aureus infections and disease.

However, S. aureus has virulence mechanisms that counteract host defenses to enable establishment of invasive $S$. aureus (ISA) disease. These mechanisms include scavenging essential nutrients, adhering to host tissues, and immune evasion (42). Therefore, for a vaccine to prevent ISA, these mechanisms also need to be taken into consideration to prevent the organism from having the opportunity to establish a productive infection.

\section{PREVIOUS VACCINE APPROACHES AND WHY THEY MAY NOT HAVE BEEN SUCCESSFUL}

Previous prophylactic S. aureus vaccines have failed in the clinic; these vaccines were composed of single antigens, either a bivalent capsular polysaccharide formulation or IsdB, and thus could only target a single virulence mechanism. Capsular polysaccharides help bacteria evade immune-mediated killing through inhibiting phagocytosis $(12,43)$. Vaccine-induced antibodies against capsular polysaccharides can overcome this virulence mechanism, but do not address other virulence mechanisms, potentially limiting the effectiveness of capsule-alone vaccine approaches. Capsular polysaccharide conjugate vaccines, such as Prevnar-13, are capable of inducing functional opsonophagocytic killing responses. The capsular polysaccharide conjugate vaccine StaphVAX did show a $57 \%$ decrease (compared to control) in incidence of bacteremia in its initial phase 3 efficacy study in hemodialysis patients. This protective effect lasted up to 40 weeks post-vaccination (44). Subsequently, in a larger phase 3 study of StaphVAX, no significant protection was observed (45). The results with StaphVAX sharply contrast the striking success of capsular polysaccharide-based vaccines in protecting against disease caused by Haemophilus influenzae type $\mathrm{B}(\mathrm{HiB})(46,47)$, Neisseria meningitidis serogroup A, C, Y, and W-135 (48-50) and Streptococcus pneumoniae $(51,52)$. There 
were many potential reasons why the StaphVAX pivotal trial failed, including the selection of the phase 3 clinical population (end stage renal disease subjects), which has a high incidence of disease but is also considered to be somewhat immunosuppressed. In addition, there may have been issues with consistency of manufacture of the phase 3 clinical trial material and the evidence that functional bacterial killing responses were elicited was weak (45). However, even if potent bacterial killing responses would have been induced, a capsular polysaccharide conjugate-alone approach may still not have been sufficient to confer protection against $S$. aureus disease due to the multiple virulence mechanisms possessed by $S$. aureus.

Likewise, a vaccine targeting IsdB may inhibit $S$. aureus acquisition of the essential nutrient iron, but it does not impact antiphagocytic virulence mechanisms. This may help explain why V710, a prophylactic monovalent vaccine composed of IsdB (53) and developed to prevent $S$. aureus infections in patients undergoing cardiothoracic surgery, failed to show significant efficacy in preventing $S$. aureus infections. A recent publication has shown that adults do generate titers to IsdB through natural exposure, and titers approximately double in hospitalized patients with $S$. aureus infections, but not other patients, indicating that IsdB is expressed during infection (54). However, the V710 IsdB vaccine does not appear to induce antibodies that efficiently induce killing of live S. aureus bacteria. Instead, antibodies induced against IsdB have only been shown to facilitate the uptake of $S$. aureus cells into neutrophils. None of the available clinical data of the V710 IsdB vaccine describe or document whether robust functional $S$. aureus killing responses were induced in the vaccine trials (55) or pre-clinically (56), with the exception of some data that individual $\mathrm{mAbs}$ recognizing Is $\mathrm{dB}$ (the vaccine's single antigen target) did show functional killing activity $(57,58)$. IsdB is generally expressed relatively late in infection in preclinical models (59), but did show some protection in lethal challenge models $(60,61)$. Stranger-Jones et al. demonstrated that the addition of IsdA, SdrD, and SdrE converted partial protection for each individual antigen to complete protection in a lethal challenge model, highlighting the potential benefits of a multiantigen approach (62). Thus, vaccines targeting a single antigen or phase of pathogenesis or infection type are not likely to be broadly protective and a multiantigen approach targeting multiple virulence mechanisms is likely required to protect against $S$. aureus infection and disease.

\section{MULTIANTIGEN VACCINE APPROACHES}

Given the low likelihood of success with a single antigen approach, Pfizer and others are currently developing multiantigen investigational $S$. aureus vaccines. Pfizer's four antigen investigational $S$. aureus vaccine (SA4Ag) is comprised of the microbial surface components recognizing adhesive matrix molecules (MSCRAMM) ClfA, the manganese transporter component MntC (aka rP305A or SA0688), and capsular polysaccharides type 5 and 8. Each antigen was carefully selected to block $S$. aureus virulence mechanisms involved in the establishment and/or maintenance of infection.

To establish ISA disease, the pathogen must first adhere to host cells, extracellular matrix, or an implanted medical device. Staphylococcal clumping factor A (ClfA), originally identified by Foster and colleagues (63), is a member of the MSCRAMM family of bacterial adhesion molecules. ClfA derives its name from its ability to induce platelet aggregation, or clumping. ClfA specifically binds to the C-terminal end of the fibrinogen $\gamma$-chain. ClfA is the major fibrinogen-binding protein in S. aureus $(9,64)$, and as such plays an important role in establishing wound and foreign body infections. Foster and colleagues elucidated that ClfA is essential during the early stages of infection and its importance as a S. aureus virulence factor has been demonstrated in several small animal models of infection, including endocarditis, arthritis, and sepsis (65-67). Interrupting ClfA binding to fibrinogen through the generation of inhibitory antibodies induced by vaccination may be beneficial in preventing the establishment of infection.

Once an infection is established, $S$. aureus must acquire essential nutrients for survival in the host microenvironment. One essential nutrient is manganese, which $S$. aureus requires for normal cell metabolism. Manganese is also a cofactor for the enzyme superoxide dismutase (SOD), which is critical for detoxifying oxygen radicals, such as those released during the bactericidal neutrophil respiratory burst. S. aureus acquires manganese via the ABC transporter complex MntABC. MntC is the metal-binding component of the complex, and is a surface-exposed lipoprotein. Indeed, recent studies have shown that MntC-deficient S. aureus is more sensitive to reactive oxygen species (68). Although $\mathrm{MntC}$ is poorly expressed in vitro, it is rapidly expressed in the host microenvironment (59) and in biofilms (69). In a study of S. aureus bacteremic patients, the median-fold increase in antibody titer against MntC from initial infection to peak titer was 5.17 , the highest of the 56 gene products surveyed. In addition, the same study showed that all 21 isolates evaluated possessed the $m n t C$ gene (70). These characteristics make $\mathrm{MntC}$ an attractive vaccine target.

Finally, once $S$. aureus has invaded the host, it must avoid elimination by the host immune system. S. aureus has many mechanisms for immune evasion, including complement-binding proteins, immunoglobulin-binding proteins, such as protein A, and leukocidins such as alpha toxin, which kill white blood cells. In addition, $S$. aureus elaborates capsular polysaccharide, which has anti-phagocytic properties. All invasive human $S$. aureus have the genes required to express either type 5 or 8 capsule (denoted CP5 and CP8, respectively), and most adults have capsular-binding antibodies, demonstrating that the capsules are expressed in vivo. Due to its highly repetitive nature, capsular antigens have high epitope density and thus are attractive candidates for prophylactic vaccines.

In addition to Pfizer's SA4Ag approach, others are also developing multiantigen vaccines targeting $S$. aureus, composed of capsular polysaccharide conjugates and/or protein antigens. Some vaccine approaches include the addition of toxins, many of which have shown preclinical efficacy in specific animal models, such as alpha toxin, PVL, SEB, and TSST (71-73). However, many toxins, including PVL, TSST, and SEB, are only expressed by a proportion of strains $(74,75)$, limiting the potential coverage afforded by these vaccine candidates. In contrast, some toxins, such as alpha toxin, also known as $\alpha$-hemolysin, are genetically conserved and thus have the potential to protect against a wide variety of $S$. aureus strains. Alpha toxin is a pore-forming $\beta$-barrel toxin, which binds to host cell receptors such as ADAM10 to initiate toxin oligomerization and pore formation. High levels of alpha toxin expression have been correlated with poor outcomes in pneumonia models. 
Alpha toxin has also been implicated in S. aureus pathogenesis in dermonecrosis and bacteremia models. Antibody therapeutics directed against alpha toxin have been shown to be effective in preclinical models $(76,77)$, so alpha toxin may be a beneficial addition to multiantigen $S$. aureus vaccines. Antitoxin approaches in general, though, are challenged by a number of factors: (1) the sheer number and redundancy of toxins produced by $S$. aureus (over 50) make selection of toxins for vaccine inclusion difficult, (2) toxins are generally produced relatively late in the infectious process, so antitoxin responses will have an effect later in the infectious cycle, after disease has been established, and (3) toxins are generally secreted factors, and thus antitoxin responses will not directly lead to killing and clearance of $S$. aureus.

The addition of an adjuvant may be beneficial, depending on the antigens selected, the desired immune response, and the target population(s) intended for vaccination. For example, if the intended population is naïve to $S$. aureus exposure or immunocompromised, addition of an adjuvant may boost immune responses. Some antigens, such as polysaccharide conjugates, generally do not require the addition of an adjuvant, while others, such as poorly immunogenic proteins, may greatly benefit from adjuvantation, even in immunocompetent subjects. Adjuvants can drive a more cell-mediated biased immune response, a more humoral biased immune response, or a balanced response, given the intrinsic properties of the adjuvant. However, the optimal adjuvant to use with a particular antigen or set of antigens or for a particular target population ultimately must be empirically determined.

\section{DEVELOPMENT OF PRECLINICAL ANIMAL MODELS AND IN VITRO ASSAYS TO ASSESS VACCINE FUNCTION}

Both careful selection of preclinical animal models and development of in vitro assays that measure functional serological responses are important for effective vaccine design.

$S$. aureus causes a wide range of disease in a variety of host microenvironments, so the preclinical development of an effective vaccine targeting $S$. aureus must involve the use of multiple preclinical in vivo models, which represent different diseases. Each model selected provides information on how the vaccine might behave clinically. In the case of $S$. aureus, end organ dissemination can be mimicked by pyelonephritis models, the response to deep tissue infections can be approximated by wound models, and bloodstream infections can be modeled by bacteremia and/or sepsis models. When selecting preclinical animal models, it is important that the model replicates salient features of the vaccine target population. For example, if the vaccine is aimed at preventing $S$. aureus pneumonia, then a pneumonia model should be evaluated pre-clinically. Ideally, non-human primate models are used, but non-human primate models are expensive and numerically limited. Small animal models have been criticized, especially in the $S$. aureus vaccine field, for not accurately predicting responses in the clinic. While it is true that all models have limitations, when used with discretion they can provide important insights into pathogenic mechanisms, host-pathogen interactions, and kinetics of antigen expression in vivo. These insights can guide vaccine antigen selection to ensure that a vaccine is broadly protective against a range of $S$. aureus disease manifestations. In the case of StaphVAX, if the new phase 3 lots for the second phase 3 trial had been tested in either preclinical models or in potencyindicating studies, an expensive and unsuccessful efficacy study might have been avoided.

Equally as important as the demonstration that an investigational $S$. aureus vaccine elicits a protective response in multiple animal models that mimic different types of $S$. aureus infection, is the use of diverse $S$. aureus isolates in preclinical models. Diseasecausing $S$. aureus are genetically diverse, and thus vaccine-induced immune responses might have varying effectiveness against genetically distinct clinical isolates. For example, disease-causing $S$. aureus possesses the genetic machinery to produce one of two capsular polysaccharide types, type 5 or 8 . Immune responses against CP5 may or may not cross-protect against CP8 isolates, and vice versa, so clinical strains expressing each capsule type need to be tested in animal models.

In addition to developing a battery of preclinical animal models that can be used to evaluate vaccine efficacy against a variety of $S$. aureus disease manifestations, it is also important to concomitantly develop in vitro assays that measure development of functional immune responses from both preclinical and clinical specimens. Assays that measure functional immune responses are preferable to assays that merely measure antigen-binding antibody, such as ELISAs. For example, functional killing antibody responses against $S$. aureus capsular polysaccharide can be detected using opsonophagocytic activity assays (OPAs). We have previously shown that $S$. aureus $\mathrm{CP}-\mathrm{CRM}_{197}$ conjugates induce robust killing OPA responses (12), and we and others have shown that capsular polysaccharide is an important immune evasion mechanism. Thus, OPA titers can be used as another measure potential protection against $S$. aureus disease.

In the case of protein antigens, an assay which measures interruption of protein function can be desirable. Functional immune responses against the $S$. aureus adhesion molecule ClfA can be measured by means of an adhesion assay using live bacteria, the fibrinogen-binding inhibition (FBI) assay. The FBI quantitates the ability of immune serum to inhibit binding of whole live $S$. aureus to fibrinogen, which occurs through the inhibition of ClfA binding to its cognate ligand. The FBI assay has been used to demonstrate that while unimmunized subjects have pre-existing high-binding antibody titers to ClfA, only very few individuals have functional antibodies that can abrogate the binding of ClfA to fibrinogen (19). For protein antigens, there is potential genetic diversity, so isolates containing disparate alleles should be tested. In addition to testing isolates that are diverse at the vaccine antigen level, it is also prudent to test isolates from diverse disease-associated clonal complexes. By including multiple clinical isolates that are genetically distinct at the antigen level as well as surveying the universe of disease-causing clonal complexes, a better sense of the possible breadth of coverage for an investigational S. aureus vaccine can be obtained.

The development of functional assays to assess immune responses to vaccine antigens yields greater insight into the quality of immune responses elicited by an investigational vaccine. Such functional assays can generally be used to measure both preclinical and clinical immune responses. Thus target values for vaccineinduced responses can be set, based on protective thresholds 
identified in preclinical animal models. If subsequently verified in the clinic, functional immunological assays can become the basis of an immune correlate of protection.

As described above, employing a wholistic, multiparameter approach to preclinical evaluation of $S$. aureus vaccine candidate antigens may be critical for development of an effective $S$. aureus vaccine. Due to the versatility of $S$. aureus as it adapts to host microenvironments, multiple preclinical models must be used which mimic aspects of human S. aureus disease. Likewise, protection needs to be demonstrated against a number of diverse $S$. aureus isolates. A successful vaccine against $S$. aureus will likely need to counter multiple virulence mechanisms, such as initial adhesion events, nutrient acquisition, and immune evasion. Monitoring efficacy of candidate antigens in multiple preclinical models provides an opportunity to understand the strengths and weaknesses of candidate antigens, and to select a set of vaccine candidates, which complement each other. The concomitant development of in vitro assays, such as the OPA, to monitor functional immune responses enables benchmarking of observations made in preclinical in vivo models with those made in the clinic. The linking of a diversity of preclinical animal models with functional in vitro assays will likely improve the probability of developing a broadly efficacious $S$. aureus vaccine.

\section{ACKNOWLEDGMENTS}

The authors wish to thank Dr. Emilio Emini (Pfizer) and Dr. William Gruber (Pfizer) for critical reading of the manuscript.

\section{REFERENCES}

1. Malachowa N, Whitney AR, Kobayashi SD, Sturdevant DE, Kennedy AD, Braughton KR, et al. Global changes in Staphylococcus aureus gene expression in human blood. PLoS One (2011) 6(4):e18617. doi:10.1371/journal.pone.0018617

2. Kluytmans J, van Belkum A, Verbrugh H. Nasal carriage of Staphylococcus aureus: epidemiology, underlying mechanisms, and associated risks. Clin Microbiol Rev (1997) 10(3):505-20.

3. Lowy FD. Staphylococcus aureus infections. N Engl J Med (1998) 339(8):520-32. doi:10.1056/NEJM199808203390806

4. Noskin GA, Rubin RJ, Schentag JJ, Kluytmans J, Hedblom EC, Jacobson C, et al. National trends in Staphylococcus aureus infection rates: impact on economic burden and mortality over a 6-year period (1998-2003). Clin Infect Dis (2007) 45(9):1132-40. doi:10.1086/522186

5. Torres VJ, Pishchany G, Humayun M, Schneewind O, Skaar EP. Staphylococcus aureus $\mathrm{Is} \mathrm{dB}$ is a hemoglobin receptor required for heme iron utilization. J Bacteriol (2006) 188(24):8421-9. doi:10.1128/JB.01335-06

6. Horsburgh MJ, Wharton SJ, Cox AG, Ingham E, Peacock S, Foster SJ. MntR modulates expression of the PerR regulon and superoxide resistance in Staphylococcus aureus through control of manganese uptake. Mol Microbiol (2002) 44(5):1269-86. doi:10.1046/j.1365-2958.2002.02944.x

7. Jonsson K, Signas C, Muller HP, Lindberg M. Two different genes encode fibronectin binding proteins in Staphylococcus aureus. The complete nucleotide sequence and characterization of the second gene. Eur J Biochem (1991) 202(3):1041-8. doi:10.1111/j.1432-1033.1991.tb16468.x

8. Massey RC, Kantzanou MN, Fowler T, Day NP, Schofield K, Wann ER, et al. Fibronectin-binding protein A of Staphylococcus aureus has multiple, substituting, binding regions that mediate adherence to fibronectin and invasion of endothelial cells. Cell Microbiol (2001) 3(12):839-51. doi:10.1046/j.1462-5822. 2001.00157.x

9. McDevitt D, Nanavaty T, House-Pompeo K, Bell E, Turner N, McIntire L, et al. Characterization of the interaction between the Staphylococcus aureus clumping factor (ClfA) and fibrinogen. Eur J Biochem (1997) 247(1):416-24. doi:10.1111/j.1432-1033.1997.00416.x
10. Ni Eidhin D, Perkins S, Francois P, Vaudaux P, Hook M, Foster TJ. Clumping factor B (ClfB), a new surface-located fibrinogen-binding adhesin of Staphylococcus aureus. Mol Microbiol (1998) 30(2):245-57. doi:10.1046/j.1365-2958. 1998.01050.x

11. Patti JM, Jonsson H, Guss B, Switalski LM, Wiberg K, Lindberg M, et al. Molecular characterization and expression of a gene encoding a Staphylococcus aureus collagen adhesin. J Biol Chem (1992) 267(7):4766-72.

12. Nanra JS, Buitrago SM, Crawford S, Ng J, Fink PS, Hawkins J, et al. Capsular polysaccharides are an important immune evasion mechanism for Staphylococcus aureus. Hum Vaccin Immunother (2012) 9(3):480-7. doi:10.4161/hv.23223

13. Smith EJ, Visai L, Kerrigan SW, Speziale P, Foster TJ. The Sbi protein is a multifunctional immune evasion factor of Staphylococcus aureus. Infect Immun (2011) 79(9):3801-9. doi:10.1128/IAI.05075-11

14. Rooijakkers SH, Ruyken M, Roos A, Daha MR, Presanis JS, Sim RB, et al. Immune evasion by a staphylococcal complement inhibitor that acts on $\mathrm{C} 3$ convertases. Nat Immunol (2005) 6(9):920-7. doi:10.1038/ni1235

15. Forsgren A, Sjoquist J. "Protein A" from S. aureus. I. Pseudo-immune reaction with human gamma-globulin. J Immunol (1966) 97(6):822-7.

16. Bhakdi S, Tranum-Jensen J. Alpha-toxin of Staphylococcus aureus. Microbiol Rev (1991) 55(4):733-51.

17. Choi YW, Kotzin B, Herron L, Callahan J, Marrack P, Kappler J. Interaction of Staphylococcus aureus toxin "superantigens" with human T cells. Proc Natl Acad Sci U S A (1989) 86(22):8941-5. doi:10.1073/pnas.86.22.8941

18. Genestier AL, Michallet MC, Prevost G, Bellot G, Chalabreysse L, Peyrol S, et al. Staphylococcus aureus Panton-Valentine leukocidin directly targets mitochondria and induces Bax-independent apoptosis of human neutrophils. J Clin Invest (2005) 115(11):3117-27. doi:10.1172/JCI22684

19. Hawkins J, Kodali S, Matsuka YV, McNeil LK, Mininni T, Scully IL, et al. A recombinant clumping factor A-containing vaccine induces functional antibodies to Staphylococcus aureus that are not observed after natural exposure. Clin Vaccine Immunol (2012) 19(10):1641-50. doi:10.1128/CVI.00354-12

20. Verdrengh M, Tarkowski A. Role of neutrophils in experimental septicemia and septic arthritis induced by Staphylococcus aureus. Infect Immun (1997) 65(7):2517-21.

21. Rigby KM, DeLeo FR. Neutrophils in innate host defense against Staphylococcus aureus infections. Semin Immunopathol (2012) 34(2):237-59. doi:10.1007/ s00281-011-0295-3

22. DeLeo FR, Diep BA, Otto M. Host defense and pathogenesis in Staphylococcus aureus infections. Infect Dis Clin North Am (2009) 23(1):17-34. doi:10.1016/j. idc. 2008.10 .003

23. von Aulock S, Morath S, Hareng L, Knapp S, van Kessel KP, van Strijp JA, et al. Lipoteichoic acid from Staphylococcus aureus is a potent stimulus for neutrophil recruitment. Immunobiology (2003) 208(4):413-22. doi:10.1078/01712985-00285

24. Takeda K, Kaisho T, Akira S. Toll-like receptors. Annu Rev Immunol (2003) 21:335-76. doi:10.1146/annurev.immunol.21.120601.141126

25. Foster TJ. Immune evasion by staphylococci. Nat Rev Microbiol (2005) 3(12):948-58. doi:10.1038/nrmicro1289

26. Bodey GP, Buckley M, Sathe YS, Freireich EJ. Quantitative relationships between circulating leukocytes and infection in patients with acute leukemia. Ann Intern Med (1966) 64(2):328-40. doi:10.7326/0003-4819-64-2-328

27. Quie PG, White JG, Holmes B, Good RA. In vitro bactericidal capacity of human polymorphonuclear leukocytes: diminished activity in chronic granulomatous disease of childhood. J Clin Invest (1967) 46(4):668-79. doi:10.1172/JCI105568

28. Johnston RB Jr, Keele BB Jr, Misra HP, Lehmeyer JE, Webb LS, Baehner RL, et al. The role of superoxide anion generation in phagocytic bactericidal activity. Studies with normal and chronic granulomatous disease leukocytes. J Clin Invest (1975) 55(6):1357-72. doi:10.1172/JCI108055

29. Heyworth PG, Cross AR, Curnutte JT. Chronic granulomatous disease. Curr Opin Immunol (2003) 15(5):578-84. doi:10.1016/S0952-7915(03)00109-2

30. Dinauer MC. Disorders of neutrophil function: an overview. Methods Mol Biol (2007) 412:489-504. doi:10.1007/978-1-59745-467-4_30

31. Lorenz E, Mira JP, Cornish KL, Arbour NC, Schwartz DA. A novel polymorphism in the toll-like receptor 2 gene and its potential association with staphylococcal infection. Infect Immun (2000) 68(11):6398-401. doi:10.1128/IAI.68.11.63986401.2000

32. Figueroa JE, Densen P. Infectious diseases associated with complement deficiencies. Clin Microbiol Rev (1991) 4(3):359-95. 
33. de Beaucoudrey L, Puel A, Filipe-Santos O, Cobat A, Ghandil P, Chrabieh M, et al. Mutations in STAT3 and IL12RB1 impair the development of human IL-17producing T cells. J Exp Med (2008) 205(7):1543-50. doi:10.1084/jem.20080321

34. Ma CS, Chew GY, Simpson N, Priyadarshi A, Wong M, Grimbacher B, et al. Deficiency of Th17 cells in hyper IgE syndrome due to mutations in STAT3. J Exp Med (2008) 205(7):1551-7. doi:10.1084/jem.20080218

35. Milner JD, Brenchley JM, Laurence A, Freeman AF, Hill BJ, Elias KM, et al. Impaired $\mathrm{T}(\mathrm{H}) 17$ cell differentiation in subjects with autosomal dominant hyper-IgE syndrome. Nature (2008) 452(7188):773-6. doi:10.1038/nature06764

36. Jacobson MA, Gellermann H, Chambers H. Staphylococcus aureus bacteremia and recurrent staphylococcal infection in patients with acquired immunodeficiency syndrome and AIDS-related complex. Am J Med (1988) 85(2):172-6. doi:10.1016/S0002-9343(88)80337-1

37. Maraqa NF, Aigbivbalu L, Masnita-Iusan C, Wludyka P, Shareef Z, Bailey C, et al. Prevalence of and risk factors for methicillin-resistant Staphylococcus aureus colonization and infection among infants at a level III neonatal intensive care unit. Am J Infect Control (2011) 39(1):35-41. doi:10.1016/j.ajic.2010.07.013

38. Mickenberg ID, Root RK, Wolff SM. Leukocytic function in hypogammaglobulinemia. J Clin Invest (1970) 49(8):1528-38. doi:10.1172/JCI106370

39. Trakultivakorn M, Ochs HD. X-linked agammaglobulinemia in northern Thailand. Asian Pac J Allergy Immunol (2006) 24(1):57-63.

40. Fauci A. Harrison's Principles of Internal Medicine. 14th ed. New York: McGrawHill Companies (1998).

41. Lin L, Ibrahim AS, Xu X, Farber JM, Avanesian V, Baquir B, et al. Th1Th17 cells mediate protective adaptive immunity against Staphylococcus aureus and Candida albicans infection in mice. PLoS Pathog (2009) 5(12):e1000703. doi:10.1371/journal.ppat.1000703

42. Anderson AS, Miller AA, Donald RG, Scully IL, Nanra JS, Cooper D, et al. Development of a multicomponent Staphylococcus aureus vaccine designed to counter multiple bacterial virulence factors. Hum Vaccin Immunother (2012) 8(11):1585-94. doi:10.4161/hv.21872

43. Thakker M, Park JS, Carey V, Lee JC. Staphylococcus aureus serotype 5 capsular polysaccharide is antiphagocytic and enhances bacterial virulence in a murine bacteremia model. Infect Immun (1998) 66(11):5183-9.

44. Shinefield H, Black S, Fattom A, Horwith G, Rasgon S, Ordonez J, et al. Use of a Staphylococcus aureus conjugate vaccine in patients receiving hemodialysis. $N$ Engl J Med (2002) 346(7):491-6. doi:10.1056/NEJMoa011297

45. Matalon AM, Buerkert J, Block G, Hohenboken M, Fattom A, Horwirth G, etal. Efficacy profile of a bivalent Staphylococcus aureus glycoconjugate investigational vaccine in adults on haemodialysis: phase III randomized study. International Symposium on Staphylococci and Staphylococcal Infections. Lyon (2012).

46. Eskola J, Peltola H, Takala AK, Kayhty H, Hakulinen M, Karanko V, et al. Efficacy of Haemophilus influenzae type b polysaccharide-diphtheria toxoid conjugate vaccine in infancy. $N$ Engl J Med (1987) 317(12):717-22. doi:10.1056/ NEJM198709173171201

47. Paradiso PR, Hogerman DA, Madore DV, Keyserling H, King J, Reisinger KS, et al. Safety and immunogenicity of a combined diphtheria, tetanus, pertussis and Haemophilus influenzae type b vaccine in young infants. Pediatrics (1993) 92(6):827-32.

48. Ramsay ME, Andrews N, Kaczmarski EB, Miller E. Efficacy of meningococcal serogroup $\mathrm{C}$ conjugate vaccine in teenagers and toddlers in England. Lancet (2001) 357(9251):195-6. doi:10.1016/S0140-6736(00)03594-7

49. Peltola H, Makela H, Kayhty H, Jousimies H, Herva E, Hallstrom K, et al. Clinical efficacy of meningococcus group A capsular polysaccharide vaccine in children three months to five years of age. N Engl J Med (1977) 297(13):686-91. doi:10.1056/NEJM197709292971302

50. Keyserling H, Papa T, Koranyi K, Ryall R, Bassily E, Bybel MJ, et al. Safety, immunogenicity, and immune memory of a novel meningococcal (groups A, $\mathrm{C}, \mathrm{Y}$, and $\mathrm{W}-135)$ polysaccharide diphtheria toxoid conjugate vaccine (MCV4) in healthy adolescents. Arch Pediatr Adolesc Med (2005) 159(10):907-13. doi:10.1001/archpedi.159.10.907

51. Shinefield HR, Black S. Efficacy of pneumococcal conjugate vaccines in large scale field trials. Pediatr Infect Dis J (2000) 19(4):394-7. doi:10.1097/00006454200004000-00036

52. Black S, Shinefield H, Fireman B, Lewis E, Ray P, Hansen JR, et al. Efficacy, safety and immunogenicity of heptavalent pneumococcal conjugate vaccine in children. Northern California Kaiser Permanente Vaccine Study Center Group. Pediatr Infect Dis J (2000) 19(3):187-95. doi:10.1097/00006454-200003000-00003
53. Harro C, Betts R, Orenstein W, Kwak EJ, Greenberg HE, Onorato MT, et al. Safety and immunogenicity of a novel Staphylococcus aureus vaccine: results from the first study of the vaccine dose range in humans. Clin Vaccine Immunol (2010) 17(12):1868-74. doi:10.1128/CVI.00356-10

54. Zorman JK, Esser M, Raedler M, Kreiswirth BN, Ala'Aldeen DA, Kartsonis N, et al. Naturally occurring IgG antibody levels to the Staphylococcus aureus protein IsdB in humans. Hum Vaccin Immunother (2013) 9(9):1857-64. doi:10.4161/hv.25253

55. Fowler VG, Allen K, Moreira E, Moustafa M, Isgro F, Boucher H, et al. Efficacy and Safety of an Investigational Staphylococcus aureus Vaccine in Preventing Bacteremia and Deep Sternal Wound Infections after Cardiothoracic Surgery. San Diego, CA: IDWeek (2012).

56. Kim HK, DeDent A, Cheng AG, McAdow M, Bagnoli F, Missiakas DM, et al. IsdA and IsdB antibodies protect mice against Staphylococcus aureus abscess formation and lethal challenge. Vaccine (2010) 28(38):6382-92. doi:10.1016/j. vaccine.2010.02.097

57. Brown M, Kowalski R, Zorman J, Wang XM, Towne V, Zhao Q, et al. Selection and characterization of murine monoclonal antibodies to Staphylococcus aureus iron-regulated surface determinant B with functional activity in vitro and in vivo. Clin Vaccine Immunol (2009) 16(8):1095-104. doi:10.1128/CVI. 00085-09

58. Ebert T, Smith S, Pancari G, Clark D, Hampton R, Secore S, et al. A fully human monoclonal antibody to Staphylococcus aureus iron regulated surface determinant B (IsdB) with functional activity in vitro and in vivo. Hum Antibodies (2010) 19(4):113-28. doi:10.3233/HAB-2010-0235

59. Anderson AS, Scully IL, Timofeyeva Y, Murphy E, McNeil LK, Mininni T, et al. Staphylococcus aureus manganese transport protein $\mathrm{C}$ is a highly conserved cell surface protein that elicits protective immunity against S. aureus and Staphylococcus epidermidis. J Infect Dis (2012) 205(11):1688-96. doi:10.1093/infdis/ jis272

60. Kuklin NA, Clark DJ, Secore S, Cook J, Cope LD, McNeely T, et al. A novel Staphylococcus aureus vaccine: iron surface determinant B induces rapid antibody responses in rhesus macaques and specific increased survival in a murine S. aureus sepsis model. Infect Immun (2006) 74(4):2215-23. doi:10.1128/IAI.74. 4.2215-2223.2006

61. Bagnoli F, Bertholet S, Grandi G. Inferring reasons for the failure of Staphylococcus aureus vaccines in clinical trials. Front Cell Infect Microbiol (2012) 2:16. doi:10.3389/fcimb.2012.00016

62. Stranger-Jones YK, Bae T, Schneewind O. Vaccine assembly from surface proteins of Staphylococcus aureus. Proc Natl Acad Sci US A (2006) 103(45):16942-7. doi:10.1073/pnas.0606863103

63. McDevitt D, Francois P, Vaudaux P, Foster TJ. Identification of the ligandbinding domain of the surface-located fibrinogen receptor (clumping factor) of Staphylococcus aureus. Mol Microbiol (1995) 16(5):895-907. doi:10.1111/j. 1365-2958.1995.tb02316.x

64. O’Brien L, Kerrigan SW, Kaw G, Hogan M, Penades J, Litt D, et al. Multiple mechanisms for the activation of human platelet aggregation by Staphylococcus aureus: roles for the clumping factors ClfA and ClfB, the serine-aspartate repeat protein SdrE and protein A. Mol Microbiol (2002) 44(4):1033-44. doi:10.1046/j.1365-2958.2002.02935.x

65. McAdow M, Kim HK, Dedent AC, Hendrickx AP, Schneewind O, Missiakas DM. Preventing Staphylococcus aureus sepsis through the inhibition of its agglutination in blood. PLoS Pathog (2011) 7(10):e1002307. doi:10.1371/journal.ppat. 1002307

66. Josefsson E, Hartford O, O’Brien L, Patti JM, Foster T. Protection against experimental Staphylococcus aureus arthritis by vaccination with clumping factor A, a novel virulence determinant. J Infect Dis (2001) 184(12):1572-80. doi:10.1086/324430

67. Moreillon P, Entenza JM, Francioli P, McDevitt D, Foster TJ, Francois P, et al. Role of Staphylococcus aureus coagulase and clumping factor in pathogenesis of experimental endocarditis. Infect Immun (1995) 63(12):4738-43.

68. Handke LD, Hawkins JC, Miller AA, Jansen KU, Anderson AS. Regulation of Staphylococcus aureus MntC expression and its role in response to oxidative stress. PLoS One (2013) 8(10):e77874. doi:10.1371/journal.pone.0077874

69. Brady RA, O’May GA, Leid JG, Prior ML, Costerton JW, Shirtliff ME. Resolution of Staphylococcus aureus biofilm infection using vaccination and antibiotic treatment. Infect Immun (2011) 79(4):1797-803. doi:10.1128/IAI. 00451-10 
70. den Reijer PM, Lemmens-den Toom N, Kant S, Snijders SV, Boelens H, Tavakol M, et al. Characterization of the humoral immune response during Staphylococcus aureus bacteremia and global gene expression by Staphylococcus aureus in human blood. PLoS One (2013) 8(1):e53391. doi:10.1371/journal. pone.0053391

71. Lowell GH, Kaminski RW, Grate S, Hunt RE, Charney C, Zimmer S, et al. Intranasal and intramuscular proteosome-staphylococcal enterotoxin B (SEB) toxoid vaccines: immunogenicity and efficacy against lethal SEB intoxication in mice. Infect Immun (1996) 64(5):1706-13.

72. Brown EL, Dumitrescu O, Thomas D, Badiou C, Koers EM, Choudhury P, et al. The Panton-Valentine leukocidin vaccine protects mice against lung and skin infections caused by Staphylococcus aureus USA300. Clin Microbiol Infect (2009) 15(2):156-64. doi:10.1111/j.1469-0691.2008.02648.x

73. Hu DL, Omoe K, Sasaki S, Sashinami H, Sakuraba H, Yokomizo Y, et al. Vaccination with nontoxic mutant toxic shock syndrome toxin 1 protects against Staphylococcus aureus infection. J Infect Dis (2003) 188(5):743-52. doi:10.1086/377308

74. Neill RJ, Fanning GR, Delahoz F, Wolff R, Gemski P. Oligonucleotide probes for detection and differentiation of Staphylococcus aureus strains containing genes for enterotoxins A, B, and C and toxic shock syndrome toxin 1. J Clin Microbiol (1990) 28(7):1514-8.

75. Lina G, Piemont Y, Godail-Gamot F, Bes M, Peter MO, Gauduchon V, et al. Involvement of Panton-Valentine leukocidin-producing Staphylococcus aureus in primary skin infections and pneumonia. Clin Infect Dis (1999) 29(5):1128-32. doi:10.1086/313461
76. Foletti D, Strop P, Shaughnessy L, Hasa-Moreno A, Casas MG, Russell M, et al. Mechanism of action and in vivo efficacy of a human-derived antibody against Staphylococcus aureus alpha-hemolysin. J Mol Biol (2013) 425(10):1641-54. doi:10.1016/j.jmb.2013.02.008

77. Hua L, Hilliard JJ, Shi Y, Tkaczyk C, Cheng LI, Yu X, et al. Assessment of an antialpha toxin $\mathrm{mAb}$ for prevention and treatment of Staphylococcus aureus induced pneumonia. Antimicrob Agents Chemother (2013). doi:10.1128/AAC.02190-13

Conflict of Interest Statement: Ingrid L. Scully, Paul A. Liberator, Kathrin U. Jansen, and Annaliesa S. Anderson are employes of Pfizer and as such may hold stock in the company.

Received: 29 January 2014; accepted: 04 March 2014; published online: 24 March 2014. Citation: Scully IL, Liberator PA, Jansen KU and Anderson AS (2014) Covering all the bases: preclinical development of an effective Staphylococcus aureus vaccine. Front. Immunol. 5:109. doi: 10.3389/fimmu.2014.00109

This article was submitted to Microbial Immunology, a section of the journal Frontiers in Immunology.

Copyright (c) 2014 Scully, Liberator, Jansen and Anderson. This is an open-access article distributed under the terms of the Creative Commons Attribution License (CC $B Y)$. The use, distribution or reproduction in other forums is permitted, provided the original author(s) or licensor are credited and that the original publication in this journal is cited, in accordance with accepted academic practice. No use, distribution or reproduction is permitted which does not comply with these terms. 